\title{
Cloning, Characterization, and Functional Expression of Phospholipase D $\alpha$ cDNA from Banana (Musa acuminate L.)
}

\author{
Li Li, ${ }^{1,2}$ Xuemei He, ${ }^{1,2}$ Jian Sun, ${ }^{1,2}$ Changbao Li, ${ }^{1,2}$ Dongning Ling, ${ }^{1}$ Jinfeng Sheng, \\ Xiangrong You, ${ }^{1}$ Jiemin Li, ${ }^{1}$ Guoming Liu, ${ }^{1}$ Fengjin Zheng, ${ }^{1}$ and Yayuan Tang ${ }^{1}$ \\ ${ }^{1}$ Agro-Food Science and Technology Research Institute, Guangxi Academy of Agricultural Sciences, 174 East Daxue Road, \\ Nanning 530007, China \\ ${ }^{2}$ Guangxi Key Laboratory of Fruits and Vegetables Storage-Processing Technology, 174 East Daxue Road, Nanning 530007, China
}

Correspondence should be addressed to Jian Sun; jiansun@gxaas.net

Received 11 June 2017; Revised 21 August 2017; Accepted 10 September 2017; Published 22 October 2017

Academic Editor: Zhenfeng Yang

Copyright (C) $2017 \mathrm{Li} \mathrm{Li} \mathrm{et} \mathrm{al.} \mathrm{This} \mathrm{is} \mathrm{an} \mathrm{open} \mathrm{access} \mathrm{article} \mathrm{distributed} \mathrm{under} \mathrm{the} \mathrm{Creative} \mathrm{Commons} \mathrm{Attribution} \mathrm{License,} \mathrm{which}$ permits unrestricted use, distribution, and reproduction in any medium, provided the original work is properly cited.

Phospholipase D (PLD) plays a key role in adaptive responses of postharvest fruits. A cDNA clone of banana (Musa acuminate L.) PLD $\alpha(M a P L D \alpha)$ was obtained by RT-PCR in this study. The MaPLD $\alpha$ gene contains a complete open reading frame (ORF) encoding a 92-kDa protein composed of 832 amino acid residues and possesses a characteristic $\mathrm{C} 2$ domain and two catalytic $\mathrm{H} \times \mathrm{K} \times \times$ $\times \mathrm{D}$ (abbr. HKD) motifs. The two HKD motifs are separated by 341 amino acid residues in the primary structure. Relatively higher PLD activity and expression of MaPLD $\alpha$ mRNA were detected in developing tissues compared to senescent or mature tissues in individual leaves, flower, stem, and fruit organs, respectively. The expression profile of PLD $\alpha$ mRNA in postharvest banana fruits at different temperatures was determined, and the MaPLD $\alpha$ mRNA reached the highest expression peak on day 5 at $25^{\circ} \mathrm{C}$ and on day 7 at $12^{\circ} \mathrm{C}$. The results provide useful information for maintaining postharvest quality and extending the storage life of banana fruit.

\section{Introduction}

Banana (Musa acuminate L.) is one of the major commercial fruit crops grown in tropics and subtropics and plays a key role in the economy of developing countries [1]. Banana fruits are widely consumed but have short shelf life (6 to 10 days) after harvest under tropical conditions because of their highly perishable nature related to membrane disruption in pericarp cells. Postharvest loss significantly reduces the commercial value of banana fruits [2]

Membrane deterioration during plant senescence is commonly associated with the progressive decrease in membrane phospholipid content. Phospholipase D (PLD) (EC 3.1.4.4) is an important enzyme that initiates membrane phospholipid degradation during ripening, senescence, and signal transduction that takes place in response to hormones and environmental stress $[3,4]$. PLD in mammalian tissues hydrolyzes phospholipids, principally phosphatidylcholine (PC), to phosphatidic acid (PA) and choline. This enzyme has been implicated in a broad range of cellular processes
$[5,6]$. PLDs in plants are classified into six gene families: $P L D \alpha, P L D \beta, P L D \gamma, P L D \delta, P L D \varepsilon$, and $P L D \zeta$ [7]. PLD $\alpha$ is the most active enzyme in the PLD family in plant tissues [8] and has been associated with the catabolism and turnover of membrane lipids [9]. PLD $\alpha$ enzymes from a number of species have been characterized, including strawberry, peach, tomato, castor, cabbage, grape, and oilseed rape [10-12].

Regulation of PLD activity has a major impact on ripening and senescence of some fruits in the Sapindaceae family [13]. Previously, we have provided molecular and physiological evidence that PLD is closely related to the senescence of longan and litchi fruits $[14,15]$. We have cloned the full-length cDNA (registered in GenBank, accession number JF791814) and studied different expression patterns of longan PLD gene family members [16]. Nevertheless, there are no reports about the effects of PLD activity on banana senescence. There is also a lack of data on characterization and functional expression of PLD cDNA in banana. It is important to study the molecular mechanism of ripening and senescence in banana fruits. Therefore, the objective of 
the present study was to determine the role of PLD $\alpha$ in the response to ripening and senescence-related signaling in banana. The $P L D \alpha$ gene was isolated and amplified by reverse-transcription polymerase chain reaction (RT-PCR); analyses of $\mathrm{PLD} \alpha$ structure and nucleotide sequence of this gene were also conducted. Moreover, PLD expression and activities in different banana organs at several developmental stages and in the fruits during ripening and senescence are reported here for the first time. Our results will provide useful information for maintaining postharvest quality and extending storage life of banana fruits via specific regulation of PLD $\alpha$ expression.

\section{Materials and Methods}

2.1. Plant Materials. Banana (Musa acuminate L.) tissues (floral bud, flower, green and senescent leaves, pseudo stem, stem, developing and mature fruits, and fruits at different postharvest stages) were collected in a commercial orchard in Nanning of Guangxi province during July 2015 and transported to the laboratory immediately. Banana fruits of similar size and of the same maturity period, without infection and physical damage, were chosen and randomly subdivided into two groups (60 fruits in each group). One group was packed into polyethylene bags $\left(0.03 \mathrm{~mm}\right.$ thick) and stored at $25^{\circ} \mathrm{C}$, and the other was packed into the polyethylene bags and stored at $12^{\circ} \mathrm{C}$. Banana pericarp tissues were collected every $2 \mathrm{~d}$, frozen in liquid nitrogen, and then stored at $-80^{\circ} \mathrm{C}$ for further analysis. Three replicates per analysis were used in the subsequent measurements.

2.2. RNA Extraction. Total RNA samples were extracted from $100 \mathrm{mg}$ of fresh banana pericarp tissues. The RNA Prep Pure Plant Kit (Tiangen Co., Beijing, China) was used, followed by RNase-free DNase treatment (TaKaRa, Dalian, China). Concentrations of total RNA were measured at 260 and $280 \mathrm{~nm}$ on a NanoDrop ${ }^{\mathrm{TM}} 1000$ spectrophotometer (NanoDrop Technologies, Wilmington, DE, USA), and the purity of the extracted total RNA was determined as the ratio of optical density at $260 \mathrm{~nm}$ to that at $280 \mathrm{~nm}\left(\mathrm{OD}_{260} / \mathrm{OD}_{280}\right)$. The integrity of total RNA was determined by electrophoresis in a $1 \%(\mathrm{w} / \mathrm{v})$ agarose gel. Isolated RNA was dissolved in $50 \mu \mathrm{L}$ of RNase-free $\mathrm{H}_{2} \mathrm{O}$ and stored at $-80^{\circ} \mathrm{C}$.

2.3. Cloning of MaPLD $\alpha c D N A$. Sequences of the PLD $\alpha$ protein from the public database were aligned to identify regions of homology using the ClustalX v.2.0.5 software [17]. A PCR product was amplified with a forward degenerate primer and a specific reverse primer, both designed using highly conserved regions of PLD $\alpha$ peptides: $5^{\prime}$-GGCGGNCCCCGCGAACCGTGG-3' and 5' -TGGTTGGTAGGCGCCCATTGC- $3^{\prime}$. Both the $5^{\prime}$ and $3^{\prime}$ ends of the cDNA were identified using the Smart-RACE cDNA Amplification Kit (Clontech, CA, USA) and the internal oligonucleotides were $5^{\prime}$ GATTGATGGTGGGGCCGC-3', $5^{\prime}$-CCGATGTGGCCCGAAGGG-3', $5^{\prime}$-GTCAGGCCGTTCAGATGG-3', $5^{\prime}$-CCATGCGTACGAGCTTCC- $3^{\prime}$, and $5^{\prime}$-CGGTTCGCGGGGTCCGCC- $3^{\prime}$. The amplicons were cloned into the pMBL-T vector $(\mathrm{MBL})$ and sequenced by Shanghai Sangon Biological
Engineering Technology Service Co., Ltd. (Shanghai, China). The identities were confirmed using software BLAST. Primers with internal SacI and KpnI restriction sites were designed to amplify the coding region of the mature protein by PCR: $5^{\prime}$-GCCGAGCTCGCTCAGAAGACACATCTCC- $3^{\prime}$ and $5^{\prime}$ GGCGGTACCCTATGAGGTAAGAATTGG- $3^{\prime}$. The PCR product obtained was subcloned into the SacI and KpnI sites of pQE-80L (Qiagen, Hilden, Germany) to produce a fusion protein with a 6 -His tag at the $\mathrm{N}$ terminus. Ligation into the correct reading frame was confirmed by sequencing. The resulting construct was designated as PQEPLD $\alpha$ [18].

2.4. Bioinformatic and Cladistic Analyses. Sequence alignments, open reading frame (ORF) translation, and molecular mass calculation of the predicted protein were performed in DNAMAN v.6.0.3.99. The putative domains of $M a P L D \alpha$ were predicted by means of Swiss-Model (https://swissmodel .expasy.org/). Swiss-Model was run in "first approach" and "project (optimize)" modes with default parameters. Structures were visualized using Swiss-PDBViewer [19]. The PLD gene family related by amino acid sequences was aligned in ClustalX v.1.81 (http://www.clustal.org/) at the default settings, and the alignment was further refined by visual inspection. A phylogenetic tree was constructed by the minimum evolution method in MEGA ver. 4.0 [20, 21]. The Poisson correction metric was used together with the pairwise deletion option. The confidence of the tree branches was checked by bootstrapping generated from 1,000 replicates.

2.5. PLD Activity. This activity was assayed by a highly specific and sensitive sandwich enzyme immunoassay technique (enzyme-linked immunosorbent assay; ELISA) [22]. Namely, 96-well ELISA microtiter plates (Shanghai, China) were coated with purified plant PLD to set up the solid-phase antibody $(100 \mu \mathrm{L}$ per well, $1 \mathrm{mg} / \mathrm{mL}$ diluted $1: 1000$ in PBS, $\mathrm{pH}$ $7.2,4^{\circ} \mathrm{C}$ ). The plates were then blocked $(2 \mathrm{~h}$ at room temperature) with $1 \%$ skimmed milk powder dissolved in PBS ( $\mathrm{pH}$ 7.4). The wells were then washed twice with $200 \mu \mathrm{L}$ of wash buffer for $10 \mathrm{~min}$. A series of PLD standards was prepared in the range $2-120 \mathrm{U} / \mathrm{L}$ in $\mathrm{PBS}(\mathrm{pH} 7.4)$. Samples were also prepared in a series of dilutions from $1 / 5$ to $1 / 50$ in PBS. The standards and samples were added to wells ( $50 \mu \mathrm{L}$ per well) and incubated for $2 \mathrm{~h}$ at $37^{\circ} \mathrm{C}$. The wells were then washed twice with $100 \mu \mathrm{L}$ of wash buffer. Conjugate binding was performed by adding a biotin-conjugated antibody specific for PLD ( $100 \mu \mathrm{L}$ of $0.1 \%$ antibody conjugate in PBS). After incubation for $1 \mathrm{~h}$ at $37^{\circ} \mathrm{C}$, the plates were washed three times with wash buffer and three times with $100 \mu \mathrm{L}$ of carbonate buffer. Horseradish peroxidase (HRP; $50 \mu \mathrm{L}$ ) was added and incubated for $15 \mathrm{~min}$ in the dark at $37^{\circ} \mathrm{C}$. The absorbance values of the plates were then read at $450 \mathrm{~nm}$. The activity of PLD in the samples was then determined by comparing the $\mathrm{OD}$ of the samples to the standard curve and expressed as $\mathrm{U} / \mathrm{mg}$.

2.6. Semiquantitative Reverse-Transcriptase (RT) PCR Anal$y$ sis. Banana tissues of the floral bud, flower, green and senescent leaves, pseudo stem, stem, developing fruit, mature fruit, and postharvest fruit were collected. The PLD mRNA 
expression patterns were determined by semiquantitative RT-PCR. Housekeeping gene actin served as an internal control (GenBank accession number AB046952). Protocols for total RNA extraction and synthesis of cDNA are described above. Gene-specific primers for PLD (PLD-S3: $5^{\prime}$-GAAATCGGGAGGTCAAGAAGAG-3'; PLD-A3: $5^{\prime}$ CTAAGTTGTGAGGATTGGAGG-3' ${ }^{\prime}$ ) and actin (forward: $5^{\prime}$-GATTCTGGTGATGGTGTGAGT-3'; reverse: $5^{\prime}$-GACAATTTCCCTTAGCAG-3 ${ }^{\prime}$ ) were employed in RT-PCR. PCR was carried out with an initial denaturation step at $94^{\circ} \mathrm{C}$ for $5 \mathrm{~min}$, and amplification was achieved via 35 cycles at $94^{\circ} \mathrm{C}$ for $30 \mathrm{~s}, 55^{\circ} \mathrm{C}$ for $30 \mathrm{~s}$, and $72^{\circ} \mathrm{C}$ for $1 \mathrm{~min}$, with a final extension at $72^{\circ} \mathrm{C}$ for $10 \mathrm{~min}$. The PCR products $(10 \mu \mathrm{L})$ were analyzed by electrophoresis in a $1 \%$ agarose gel.

2.7. Statistical Analysis. All the experiments were conducted in triplicate $(n=3)$ and were arranged in a completely randomized design. All statistical analyses were based on analysis of variance (ANOVA) in the SPSS 13.0 statistical software (SPSS Inc., Chicago, USA). Significance of differences between the means of parameters was determined by Fisher's least significant difference (LSD) test $(P<0.05)$. The results are presented as mean \pm standard error $(\mathrm{SE})$ of three replicates.

\section{Results}

3.1. Isolation and Sequence Analysis of MaPLD $\alpha$. In this study, the conserved regions from available $P L D \alpha$ sequences were used to design specific primers for $P L D \alpha$. Using these primers, a 1246-bp fragment from banana pericarp cDNA was amplified by RT-PCR, which corresponded to the PLD $\alpha$ mRNA internal region. The $5^{\prime}$ and $3^{\prime}$ flanking sequences obtained by RACE were assembled with those of the consensus region to form the full-length cDNA sequence. The full-length cDNA of MaPLD $\alpha$ was found to be 2916 bp long, including a putative ORF of $2680 \mathrm{bp}$, a $3^{\prime}$ untranslated region of $295 \mathrm{bp}$, and a poly-A tail. The translated protein encoded by $M a P L D \alpha$ contains 832 amino acid residues (aa) with a calculated molecular mass of $92 \mathrm{kDa}$ and an isoelectric point $\left(\mathrm{P}_{\mathrm{I}}\right)$ of 5.9 .

On the basis of a BLASTp homology search, the deduced amino acid sequence of MaPLD $\alpha$ showed $87 \%$ identity to PLD $\alpha$ from Zea mays (GenBank accession number BAA11135.1), 86\% identity to PLD $\alpha$ from Oryza sativa Japonica Group (GenBank accession number BAA11136.1), and 82\% identity to PLD $\alpha$ from Ricinus communis (GenBank accession number AAB04095.1). The multiple sequence alignment of banana PLD $\alpha$ with other PLD $\alpha$ enzymes from higher plants was conducted in the ClustalX 1.81 software and the phylogenetic tree was generated in MEGA 4.0 (Figure 1). All these results suggested that $\mathrm{MaPLD} \alpha$ shares high identity with other plant PLD $\alpha$ enzymes, indicating that it is a member of the PLD $\alpha$ superfamily.

3.2. Bioinformatic Analysis. The predicted MaPLD $\alpha$ protein contained three conserved domains: the C2 domain (protein kinase $\mathrm{C}$ conserved region 2) and two PLDc domains that possess duplicated $\mathrm{H} \times \mathrm{K} \times \times \times \mathrm{D}$ motifs (abbr. HKD motifs).
The C2 domain is present in all cloned plant PLDs, but not in yeast or animal PLDs. C2 is a $\mathrm{Ca}^{2+}$-dependent phospholipidbinding structural fold, and this binding is coordinated by 4-5 aa present in two bipartite loops of the domain [23]. In Arabidopsis, $\mathrm{Ca}^{2+}$ binds to the $\mathrm{C} 2$ domain of PLD $\alpha 1$; then a conformation change and an increase in C2's affinity for PC are induced by this binding [24].

All PLDs contain two HKD motifs and conserved amino acid residues (His, Lys, and Asp) form a catalytic triad responsible for the hydrolysis of phosphoester bonds [25]. Site-directed mutagenesis of PLD from several species has indicated that these amino acids are critical for catalysis in vitro and for PLD functions [23]. The first active site having the amino acid sequence HQKIVIVD was identified in the region 315-322 (amino acid positions) in banana $\operatorname{PLD} \alpha$, and the second active site was located further downstream comprising amino acid positions 663-670 with the sequence HTKMMIVD. The two HKD motifs of MaPLD $\alpha$ are separated at amino acid residue 341 in the primary structure. The characteristic HKD motif has been used to define the PLD family [26]. Immediately following the second HKD motif, a highly conserved sequence, IGSANINQR, contains an invariant serine residue that was proposed to be the nucleophile attacking the phosphorus atom of substrate phospholipids.

The tertiary structure of MaPLD $\alpha$ was predicted here on the basis of the segment crystal structure data on PLDs from other plants, such as Zea mays, whose structure fragments can be found in Swiss-Model. The tertiary structural model of MaPLD $\alpha$ was built using amino acid sequence with a deletion of the $\mathrm{C}$ terminus of 112 aa (positions 753-865), using protein modeling software according to the homology with proteins with known crystal structure (Swiss-Model and 3D-JIGSAW) $[27,28]$.

3.3. Expression Analysis of MaPLD $\alpha$ Gene in Different Organs. PLD activity variations were observed in different tissues of the same plant and in the same tissue at different developmental stages. As shown in Figure 2, PLD activity of green leaves was higher than that in senescent leaves, PLD activity of floral buds was higher than that in flowers, and PLD activity of stems was higher than that in pseudo stems. A relatively higher PLD activity was found in developing fruits compared to mature fruits. A similar pattern with respect to expression of $M a P L D \alpha$ was observed by semiquantitative RT-PCR using gene-specific primers. The highest mRNA expression of MaPLD $\alpha$ was found in both floral buds and flowers, and it was intermediate in fruits, low in leaves, and exceedingly low in stems (Figure 3). Relatively higher expression of $M a P L D \alpha$ mRNA was detected in developing tissues compared to senescent or mature tissues in individual leaves, flower, stem, and fruit organs, respectively. The expression of $M a P L D \alpha$ mRNA in green leaves was 1.73fold higher than that in senescent leaves, the expression in floral buds was 1.1-fold higher than that in flowers, and the expression in stems was 1.3-fold higher than that in pseudo stems. Meanwhile the expression in developing fruits at different stages was also higher than that in mature fruits. 


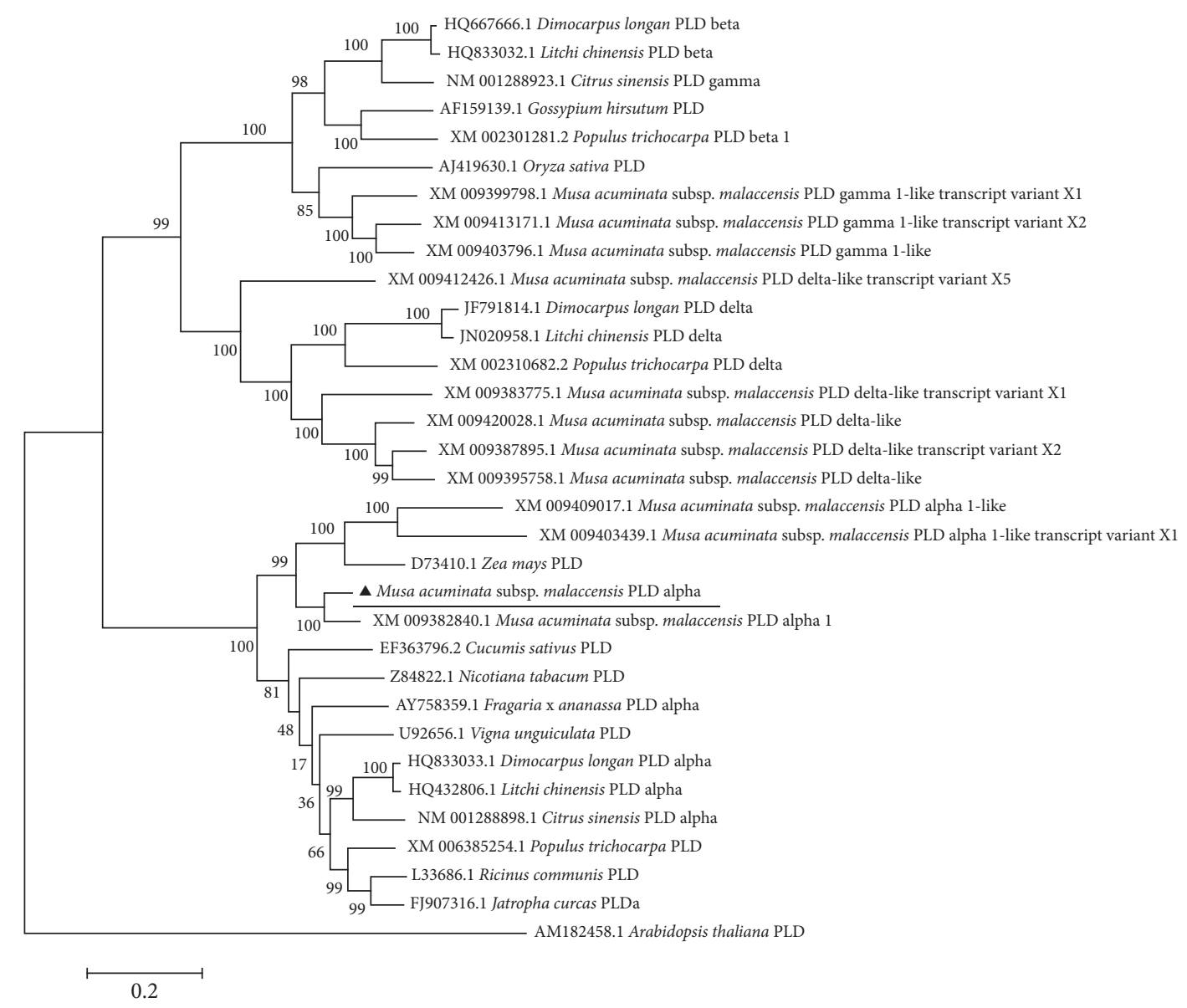

FIGUre 1: Phylogenetic analysis of MaPLD $\alpha$ and related PLD proteins (PLD $\alpha$, PLD $\beta, \operatorname{PLD} \gamma$, and PLD $\delta$ ) from different plants based on alignments of amino acid sequences. The minimum evolution tree was constructed by means of MEGA 4.0. All the sequences are labeled with names and GenBank accession numbers.

3.4. Expression Analysis of the MaPLD $\alpha$ Gene at Different Postharvest Stages. As shown in Figure 4, PLD activities in banana fruits stored at 25 and $12^{\circ} \mathrm{C}$ attained a maximum on day $3(126.71 \pm 6.58 \mathrm{U} / \mathrm{L})$ and day $25(415.91 \pm 3.47 \mathrm{U} / \mathrm{L})$, respectively. Banana fruits stored at $12^{\circ} \mathrm{C}$ had relatively higher PLD activities than the fruits stored at $25^{\circ} \mathrm{C}$, indicating that this enzyme was active at low temperature. The increased PLD activity might be involved in the loss of membrane function associated with ripening and senescence in banana fruits. The expression profiles of the PLD $\alpha$ gene in banana fruits stored at 25 and $12^{\circ} \mathrm{C}$ were investigated further by semiquantitative RT-PCR. The accumulation of $P L D \alpha$ mRNA in postharvest banana fruits at different temperatures was determined. The expression of the MaPLD $\alpha$ protein was found to be upregulated with the extended storage time at $25^{\circ} \mathrm{C}$. From Figure 5, it reached the expression peak on day 5 (1.63-fold relative to the control sample on day 1 ) and then decreased on day 7 (0.51-fold relative to the highest expression on day 5). The expression of MaPLD $\alpha$ reached a maximum on day 7 at $12^{\circ} \mathrm{C}$ before decreasing to the control level (5.18-fold relative to the control sample on day 1).

\section{Discussion}

PLDs have been implicated in different cellular processes in plant growth, development, and stress responses. The subdivision of PLDs based on sequence alignment concomitantly produces groups of PLDs with common catalytic properties and gene structures. PLD $\alpha$ is the conventional plant phospholipase $\mathrm{D}$, the characteristic feature of which is the necessity of millimolar $\mathrm{Ca}^{2+}$ for optimal activity in vitro. Some studies suggest that the amino acid and nucleotide sequences of $P L D \beta$ and $P L D \gamma$ are related more closely to each other than to $P L D \alpha$ [7]. The gene structures of Arabidopsis $P L D a$, castor bean $P L D$, and rice $P L D 1$ have been revealed and share the same gene architecture [29]. The MaPLD $\alpha$ protein is highly homologous to other known members of the PLD $\alpha$ family (Figure 1). This study showed that PLD $\alpha$ enzymes from different plant species share the same genetic lineage and may have the same catalytic and functional properties.

The predicted $\mathrm{PLD} \alpha$ protein possesses three conserved domains, the C2 domain and two PLDc domains, which contain a duplicated HKD motif. The PLD $\alpha$ s cloned from eukaryotes all contain two HKD motifs [30], and they were found to be separated by approximately 321 aa in MaPLD $\alpha$. 


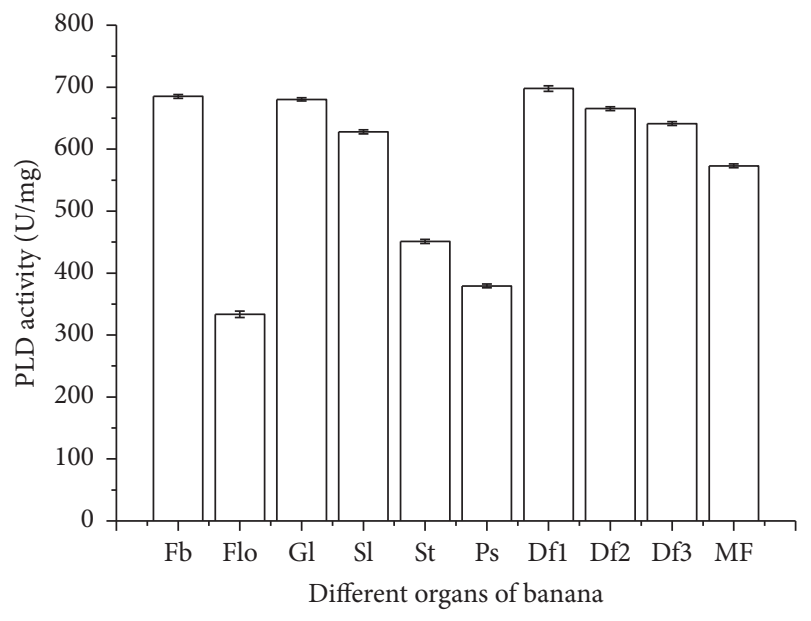

Figure 2: PLD activity of different banana organs, floral buds (Fb), flowers (Flo), green leaves ( $\mathrm{Gl})$, senescent leaves ( $\mathrm{Sl})$, pseudo stem (Ps), stem (St), developing fruits at the broken bud stage (Df1), 30 days after the broken bud stage (Df2), and 60 days after the broken bud stage (Df3), and mature fruits (Mf).

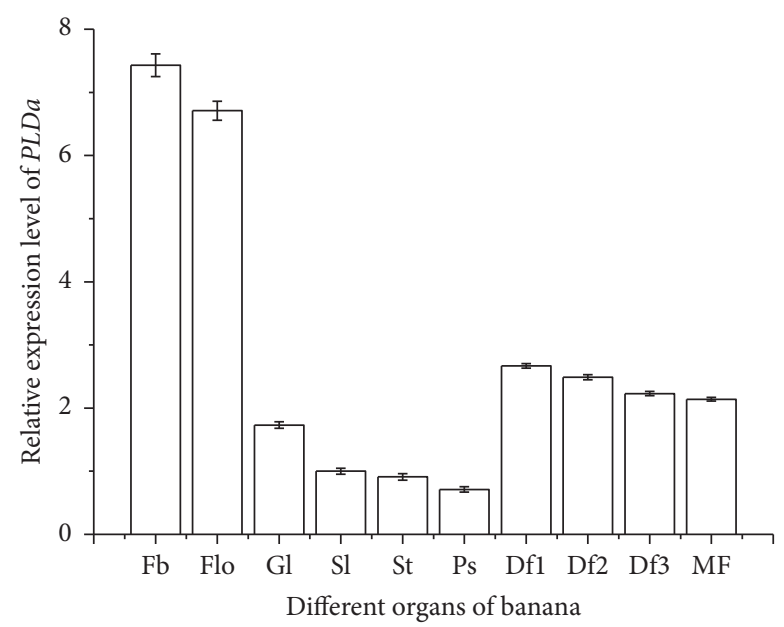

FIGURE 3: Expression of gene MaPLD $\alpha$ in different banana organs. Equivalent cDNA amounts from different banana organs, that is, floral buds $(\mathrm{Fb})$, flowers (Flo), green leaves $(\mathrm{Gl})$, senescent leaves (Sl), pseudo stem (Ps), stem (St), developing fruits at the broken bud stage (Df1), 30 days after the broken bud stage (Df2), and 60 days after the broken bud stage (Df3), and mature fruits (Mf), were analyzed by semiquantitative PCR as described in Materials and Methods, using primers specific for MaPLD $\alpha$ and a housekeeping gene, actin, as an internal control. Expression levels are presented relative to that of senescent leaves, with a standard deviation $(n=5)$.

The absolute conservation of certain amino acid positions indicated that His, Lys, and Asp are active site residues. The necessity of these residues for PLD activity has been documented by site-specific mutagenesis in yeast PLD, and changes in one of the residues may lead to the loss of PLD activity [7]. The presence of the HKD motif is usually used to define members of the PLD superfamily. Immediately following the second HKD motif and in the middle of the highly conserved sequence IGSANINQR, there is an

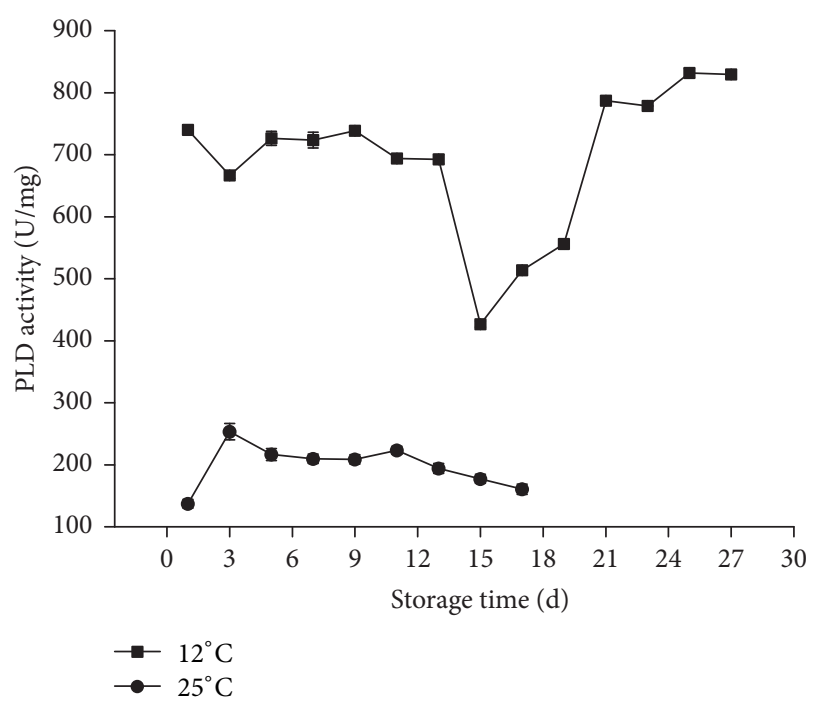

FIGURE 4: PLD activity stored for different periods at 25 or $12^{\circ} \mathrm{C}$.

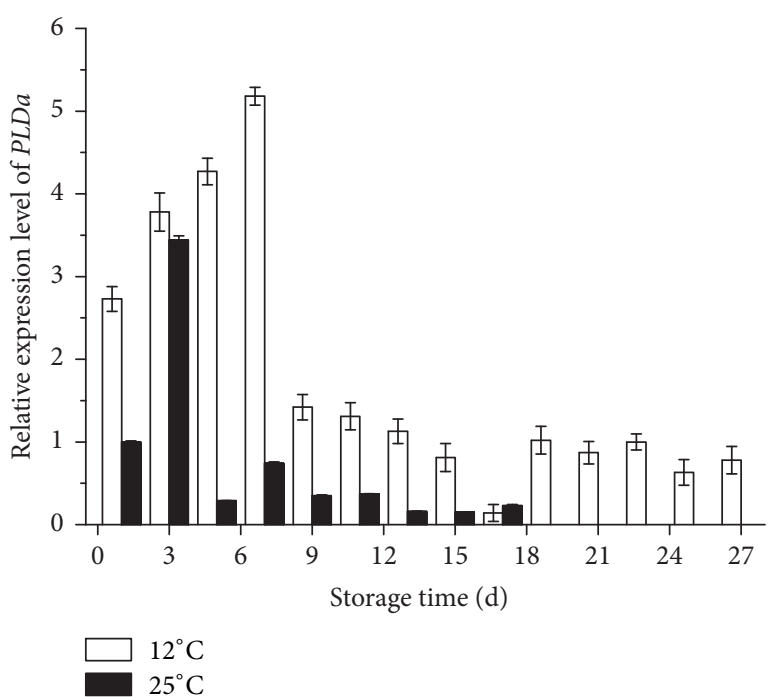

FIgURE 5: Expression of gene $M a P L D \alpha$ at different postharvest stages at 25 or $12^{\circ} \mathrm{C}$. Actin (accession number AB046952) served as an internal control.

invariant serine residue. Recent structural research has led to expansion of the active site motif in the PLD family to $\mathrm{H} \times \mathrm{K} \times \times \times \mathrm{D} \times \times \times \times \times \times \mathrm{GS} \times \mathrm{N}[31]$.

$\operatorname{PLD} \alpha$ has long been known to be present in soluble and membrane-associated fractions, and its relative distribution between the two fractions varies depending on tissues and developmental stages $[7,13]$. Centrifugal fractionation has revealed that most of $\mathrm{PLD} \alpha$ in young castor bean leaves is soluble, whereas the bulk of $\mathrm{PLD} \alpha$ in mature leaves is associated with microsomal membranes [32]. PLD promoter in vegetative tissues is highly active in the rapidly growing regions such as shoot apexes and the secondary meristem producing axillary buds and vascular tissues of young leaves and stems [7]. In banana, the appearance of $P L D \alpha$ variants is associated with developmental stages and stress conditions 
[16]. In this study, relatively higher PLD activity was detected in developing tissues compared to senescent or mature tissues in individual leaves, flower, stem, and fruit organs, respectively (Figure 2). A similar pattern with respect to expression of MaPLD $\alpha$ mRNA was observed by semiquantitative RT-PCR. The level of MaPLD $\alpha$ mRNA expression was found to be higher in developing tissues like floral buds, young leaves, stem, and developing fruits than that in senescent tissues like senescent flowers, old leaves, pseudo stems, and mature fruits (Figure 3). Similar circumstance was found in other plants; for example, the expression level was higher in young leaves than that in old leaves in Arabidopsis [7]. PLD expression and activity are intimately linked to ripening and senescence. The activity PLD was high in expanding tissues with high biosynthetic activity, supporting its possible role in either lipid biosynthesis or the regulation of signals necessary for the formation of new tissues. In this study, PLD activity correlated well with gene expression of $M a P L D \alpha$ (Figures 2 and 3). Promoter and RNA analyses discussed earlier have indicated that gene expression performs an important function in regulating PLD activity [13].

The PLD-mediated lipid degradation has been proposed to play a role in membrane degradation in tissue senescence. Increased PLD activity and PA formation have been observed with several systems including tomato fruits, cabbage leaves, and ageing seeds [17]. The pattern of $P L D \alpha$ gene expression actually argues against a general role of the most common PLD as a promoter of natural plant senescence [7]. The $\mathrm{PLD} \alpha$ promoter activity is higher in metabolically active tissues, such as meristematic and newly divided cells, than in mature and senescent ones. PLD $\alpha$ participates in the senescence of postharvest banana fruits, and PLD activity and its mRNA expression showed an increasing trend during the process, thereby leading to the damage of cell membrane integrity and postharvest fruit quality (Figures 4 and 5). PLD activity and expression of MaPLD $\alpha$ in banana fruits stored at $25^{\circ} \mathrm{C}$ were significantly higher than at $12^{\circ} \mathrm{C}$, indicating that low temperature may somewhat activate the expression of $P L D \alpha$ of banana fruits. During earlier storage time, there is an increase in PLD expression, leading to the increased accumulation of transcripts, the increased PLD protein levels, and a higher PLD activity [33]. PLD $\alpha$ is inhibited by $\mathrm{G}_{\alpha}$ proteins that produce important secondary messengers in plants: abscisic acid (ABA) involved in phytohormone signal transduction pathways [34]. Suppression of PLD $\alpha$ in Arabidopsis increases the period during which ABA and ethylene promote senescence [35], and similar studies have also revealed a role of this enzyme in plant responses to abiotic stress. The function of ethylene in banana ripening is well documented; thus, manipulation of $\operatorname{PLD} \alpha$ may maintain postharvest quality and extend storage life. Further research is needed to genetically and physiologically characterize $\mathrm{PLD} \alpha$ in banana and to gain a better understanding of its function and relation with environmental stress. Additionally, the application of molecular biology on inhibiting PLD activity and expression of $P L D \alpha$ in banana also needs further investigation.

\section{Conflicts of Interest}

The authors declare that they have no conflicts of interest.

\section{Acknowledgments}

This research was supported by the Agroscientific Research in the Public Interest (Grant no. 201303073), National Natural Science Foundation of China (Grant nos. 31160407, 31000927, 31560467, 31660589, and 31560006), Earmarked Fund for China Agriculture Research System (car-31), Bagui Scholars Project Special Fund (Grant no. [2016] 21), Technology Foundation for Selected Overseas Chinese Scholar, Ministry of Personnel of China (Grant no. Ren She Ting Han [2015] 192), Guangxi Natural Science Foundation (Grant nos. 2014GXNSFDA118013 and 2015GXNSFBA139102), Guangxi Agricultural Key Science and Technology Program (Grant no. 201527), Guangxi Scientific Research and Technological Development Projects (Grant nos. Gui Ke AD16380015 and 15104001-2), and Foundation of Fundamental Research Project from Guangxi Academy of Agricultural Sciences (Grant nos. 2015YT86, 2016JZ11, and 2017JZ10).

\section{References}

[1] R. Mendoza, D. A. Castellanos, J. C. García, J. C. Vargas, and A. O. Herrera, "Ethylene production, respiration and gas exchange modelling in modified atmosphere packaging for banana fruits," International Journal of Food Science \& Technology, vol. 51, no. 3, pp. 777-788, 2016.

[2] M. Hailu, T. S. Workneh, and D. Belew, "Review on postharvest technology of banana fruit," African Journal of Biotechnology, vol. 12, no. 7, pp. 635-647, 2013.

[3] B. O. R. Bargmann and T. Munnik, "The role of phospholipase $\mathrm{D}$ in plant stress responses," Current Opinion in Plant Biology, vol. 9, no. 5, pp. 515-522, 2006.

[4] N. Yang, X. L. Yue, X. L. Chen, G. F. Wu, T. G. Zhang, and L. Z. An, "Molecular cloning and partial characterization of a novel phospholipase D gene from Chorispora bungeana," Plant Cell, Tissue and Organ Culture, vol. 108, no. 2, pp. 201-212, 2012.

[5] X. Wang, "The role of phospholipase D in signal transduction cascade," Plant Physiology, vol. 121, pp. 456-462, 1999.

[6] N. Yang, F.-X. Ding, G.-F. Wu, C.-L. Wang, L. Ding, and L.Z. An, "Phospholipase $\mathrm{D} \alpha$ from Chorispora bungeana: cloning and partial functional characterization," Plant Growth Regulation, vol. 75, no. 2, pp. 511-520, 2015.

[7] X. Wang, "Multiple forms of phospholipase D in plants: the gene family, catalytic and regulatory properties, and cellular functions," Progress in Lipid Research, vol. 39, no. 2, pp. 109-149, 2000.

[8] W. Zhang, C. Qin, J. Zhao, and X. Wang, "Phospholipase $\mathrm{D} \alpha 1$-derived phosphatidic acid interacts with ABI1 phosphatase $2 \mathrm{C}$ and regulates abscisic acid signaling," Proceedings of the National Acadamy of Sciences of the United States of America, vol. 101, no. 25, pp. 9508-9513, 2004.

[9] X. Wang, "Phospholipase D in hormonal and stress signaling," Current Opinion in Plant Biology, vol. 5, no. 5, pp. 408-414, 2002.

[10] S. Wan, W. Wang, P. Wen et al., "Cloning of phospholipase D from grape berry and its expression under heat acclimation," BMB Reports, vol. 40, no. 4, pp. 595-603, 2007. 
[11] D. U. Kim, T. Y. Roh, J. N. Lee, Y. J. Jang, and K. L. Hoe, "Molecular cloning and functional expression of a phospholipase D from cabbage (Brassica oleracea varcapitata)," Biochimica et Biophysica Acta, vol. 1437, pp. 409-414, 1999.

[12] B. D. Whitaker, D. L. Smith, and K. C. Green, "Cloning, characterization and functional expression of a phospholipase $\mathrm{D} \alpha$ cDNA from tomato fruit," Physiologia Plantarum, vol. 112, no. 1, pp. 87-94, 2001.

[13] X. Wang, "Regulatory functions of phospholipase D and phosphatidic acid in plant growth, development, and stress responses," Plant Physiology, vol. 139, no. 2, pp. 566-573, 2005.

[14] J. Sun, X. You, L. Li et al., "Effects of a phospholipase D inhibitor on postharvest enzymatic browning and oxidative stress of litchi fruit," Postharvest Biology and Technology, vol. 62, no. 3, pp. 288294, 2011.

[15] L. Li, J. Li, J. Sun et al., "Effects of 2-butanol on quality and physiological characteristics of longan fruit stored at ambient temperature," Postharvest Biology and Technology, vol. 101, pp. 96-102, 2015.

[16] X. You, Y. Zhang, L. Li et al., "Cloning and molecular characterization of phospholipase D (PLD) delta gene from longan (Dimocarpus longan Lour.)," Molecular Biology Reports, vol. 41, no. 7, pp. 4351-4360, 2014.

[17] J. D. Thompson, T. J. Gibson, F. Plewniak, F. Jeanmougin, and D. G. Higgins, "The CLUSTAL X windows interface: flexible strategies for multiple sequence alignment aided by quality analysis tools," Nucleic Acids Research, vol. 25, no. 24, pp. 48764882, 1997.

[18] Z. L. Ma, X. P. Gu, Y. M. Zeng, and Y. Zhang, "Effect of sodium hydroxybutyrate on the expression of hippocampal Nmethyl-D-aspartate receptor 2B subunit mRNA in neonatal rats with hypoxic-ischemic insult," Annals of Clinical and Laboratory Science, vol. 36, no. 3, pp. 307-311, 2006.

[19] N. Guex and M. C. Peitsch, "SWISS-MODEL and the SwissPdbViewer: an environment for comparative protein modeling," Electrophoresis, vol. 18, no. 15, pp. 2714-2723, 1997.

[20] A. Rzhetsky and M. Nei, "A simple method for estimating and testing minimum-evolution trees," Molecular Biology and Evolution, vol. 9, no. 5, pp. 945-967, 1992.

[21] K. Tamura, J. Dudley, M. Nei, and S. Kumar, "MEGA4: molecular evolutionary genetics analysis (MEGA) software version 4.0," Molecular Biology and Evolution, vol. 24, no. 8, pp. 15961599, 2007.

[22] G. M. Smith, R. L. Ward, L. Mcguigan, I. A. Rajkovic, and K. F. Scott, "Measurement of human phospholipase a in arthritis plasma using a newly developed sandwich elisa," Rheumatology, vol. 31, no. 3, pp. 175-178, 1992.

[23] C. P. Ponting and I. D. Kerr, "A novel family of phospholipase D homologues that includes phospholipid synthases and putative endonucleases: Identification of duplicated repeats and potential active site residues," Protein Science, vol. 5, no. 5, pp. 914922, 1996.

[24] L. Zheng, R. Krishnamoorthi, M. Zolkiewski, and X. Wang, "Distinct $\mathrm{Ca}^{2+}$ binding properties of novel C2 domains of plant phospholipase $\mathrm{D} \alpha$ and $\beta$," The Journal of Biological Chemistry, vol. 275, no. 26, pp. 19700-19706, 2000.

[25] X. Wang, "Molecular analysis of phospholipase D," Trends in Plant Science, vol. 2, no. 7, pp. 261-266, 1997.

[26] T.-C. Sung, R. L. Roper, Y. Zhang et al., "Mutagenesis of phospholipase D defines a superfamily including a transGolgi viral protein required for poxvirus pathogenicity," EMBO Journal, vol. 16, no. 15, pp. 4519-4530, 1997.
[27] T. Schwede, J. Kopp, N. Guex, and M. C. Peitsch, "SWISSMODEL: an automated protein homology-modeling server," Nucleic Acids Research, vol. 31, no. 13, pp. 3381-3385, 2003.

[28] P. A. Bates, L. A. Kelley, R. M. MacCallum, and M. J. E. Sternberg, "Enhancement of protein modeling by human intervention in applying the automatic programs 3D-JIGSAW and 3D-PSSM," Proteins: Structure, Function, and Genetics, vol. 45, no. 5, pp. 39-46, 2001.

[29] A. J. Moreno-Pérez, E. Martínez-Force, R. Garcés, and J. J. Salas, "Phospholipase D $\alpha$ from sunflower (Helianthus annuus): cloning and functional characterization," Journal of Plant Physiology, vol. 167, no. 7, pp. 503-511, 2010.

[30] T. Munnik, S. A. Arisz, T. De Vrije, and A. Musgrave, "G protein activation stimulates phospholipase $\mathrm{D}$ signaling in plants," The Plant Cell, vol. 7, no. 12, pp. 2197-2210, 1995.

[31] J. A. Stuckey and J. E. Dixon, "Crystal structure of a phospholipase D family member," Nature Structural Biology, vol. 6, no. 3, pp. 278-284, 1999.

[32] L. Fan, S. Zheng, D. Cui, and X. Wang, "Subcellular distribution and tissue expression of phospholipase $\mathrm{D} \alpha, \mathrm{D} \beta$, and $\mathrm{D} \gamma$ in arabidopsis," Plant Physiology, vol. 119, no. 4, pp. 1371-1378, 1999.

[33] S. B. Ryu and X. Wang, "Expression of phospholipase D during castor bean leaf senescence," Plant Physiology, vol. 108, no. 2, pp. 713-719, 1995.

[34] L. Fan, S. Zheng, and X. Wang, "Antisense suppression of phospholipase $\mathrm{D} \alpha$ retards abscisic acid- and ethylene-promoted senescence of postharvest arabidopsis leaves," The Plant Cell, vol. 9, no. 12, pp. 2183-2196, 1997.

[35] S. B. Ryu, L. Zheng, and X. Wang, "Changes in phospholipase $\mathrm{D}$ experession in soybeans during seed development and germination," Journal of the American Oil Chemists' Society, vol. 73, no. 9, pp. 1171-1176, 1996. 

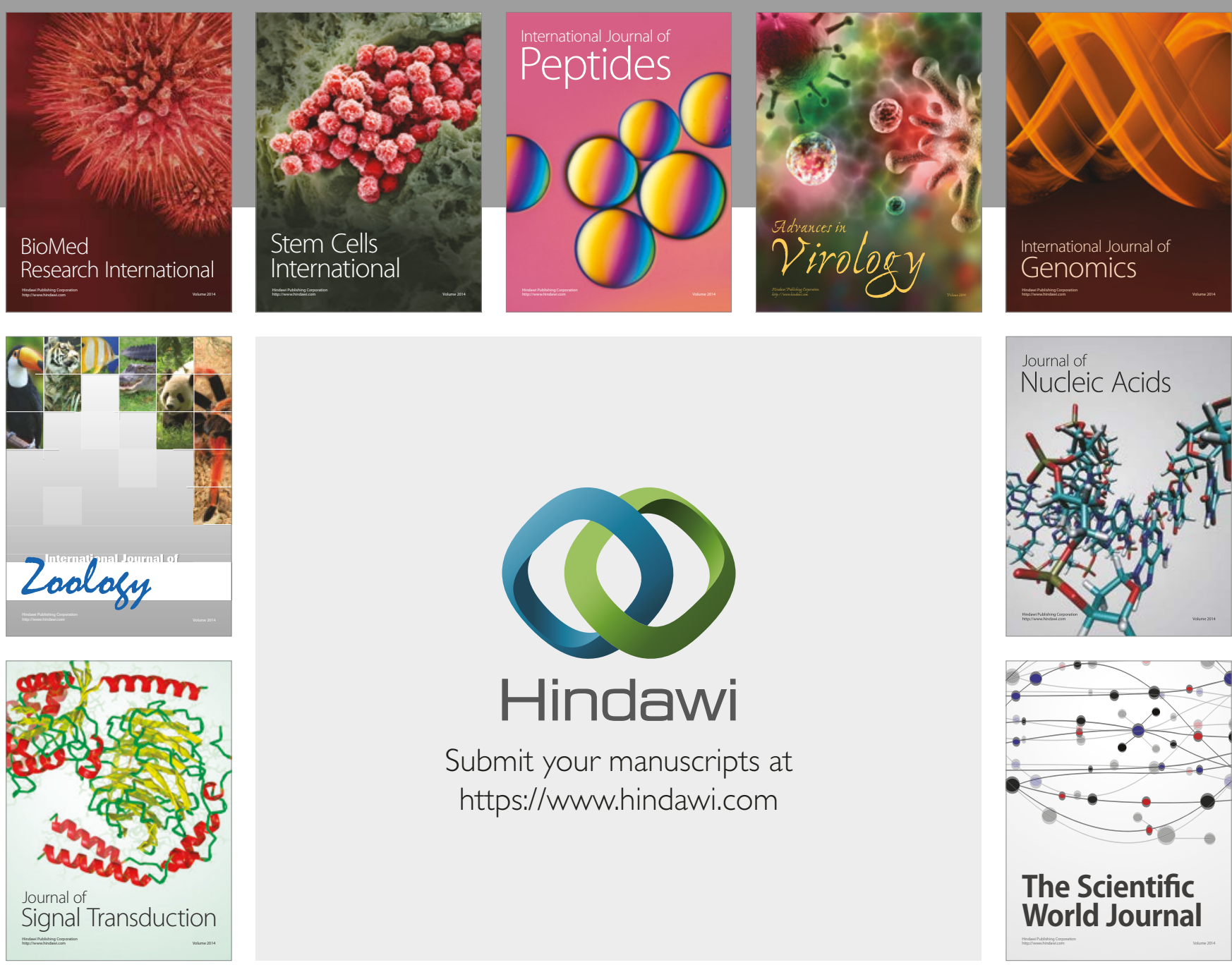

Submit your manuscripts at

https://www.hindawi.com
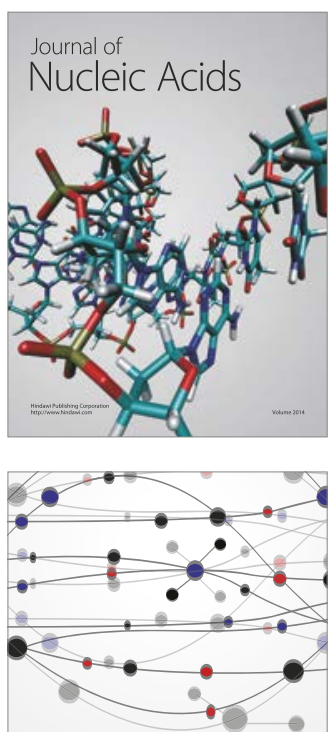

The Scientific World Journal

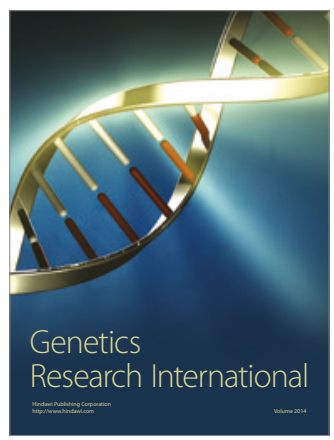

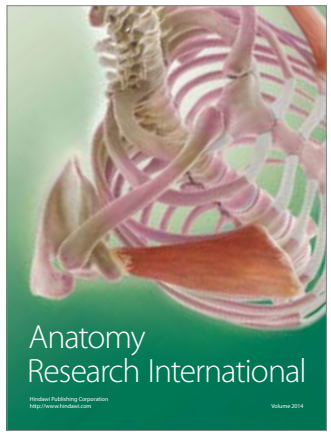

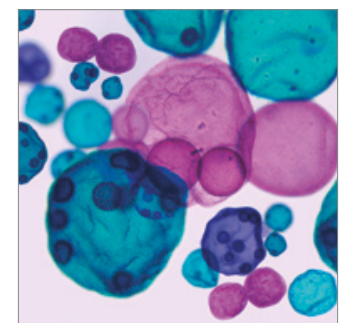

International Journal of Microbiology
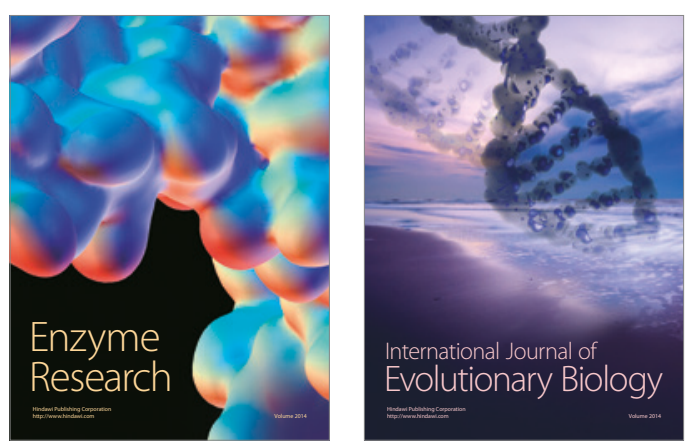
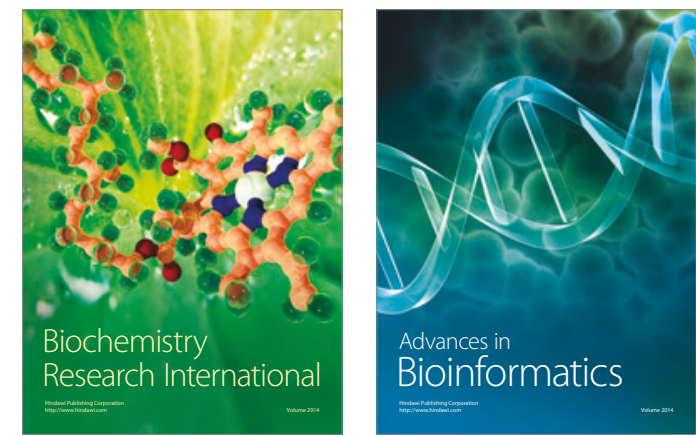

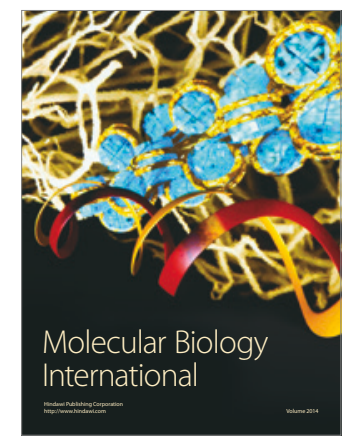

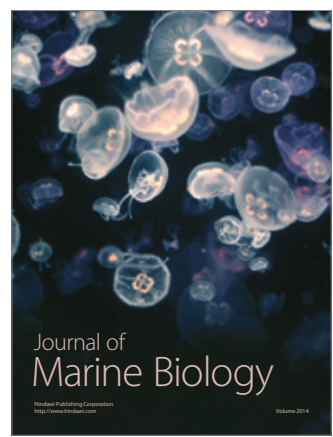

